\title{
Fixed Points Theorems in G-metric Spaces
}

\author{
Avinash Chandra Upadhyaya \\ Department of Mathematics \\ Deenbandhu ChhotuRam \\ University of Science and Technology, \\ Murthal,Sonepat-131039, \\ Haryana (India)
}

\begin{abstract}
In this paper, we prove common fixed point theorems for a pair of mappings satisfying contractive condition of integral type in G- metric spaces.
\end{abstract}

\section{Keywords}

G-metric spaces, fixed point, integral type contractive condition.

\section{INTRODUCTION}

In 2004, Mustafa and Sims [4] introduced the concept of Gmetric spaces as follows:

Let $\mathrm{X}$ be a nonempty set. Let $\mathrm{G}: \mathrm{X} \times \mathrm{X} \times \mathrm{X} \rightarrow \mathrm{R}^{+}$be a function satisfying the following properties:

$$
\begin{aligned}
& \text { (G1) } \quad G(x, y, z)=0 \text { if } x=y=z, \\
& \text { (G2) } \quad 0<G(x, x, y) \text { for all } x, y \in X \text { with } x \neq y, \\
& \text { (G3) } G(x, x, y) \leq G(x, y, z) \text { for all } x, y, z \in X \\
& \text { with } \mathrm{z} \neq \mathrm{y}, \\
& \begin{array}{ll}
\text { (G4) } & \mathrm{G}(\mathrm{x}, \mathrm{y}, \mathrm{z})=\mathrm{G}(\mathrm{x}, \mathrm{z}, \mathrm{y})=\mathrm{G}(\mathrm{y}, \mathrm{z}, \mathrm{x})=\ldots \\
& (\text { symmetry in all three variables), } \\
\text { (G5) } & \mathrm{G}(\mathrm{x}, \mathrm{y}, \mathrm{z}) \leq \mathrm{G}(\mathrm{x}, \mathrm{a}, \mathrm{a})+\mathrm{G}(\mathrm{a}, \mathrm{y}, \mathrm{z}) \text { for all } \\
& \mathrm{x}, \mathrm{y}, \mathrm{z}, \mathrm{a} \in \mathrm{X}, \text { (rectangle inequality). }
\end{array}
\end{aligned}
$$

The function $G$ is called a generalized metric or, more specifically, a $G$ - metric on $X$, and the pair $(X, G)$ is called a $\mathrm{G}-$ metric space.

Definition 1.1. Let $(X, G)$ be a G-metric space then for $x_{0} \in$ $\mathrm{X}, \mathrm{r}>0$, the G-ball with center $\mathrm{x}_{0}$ and radius $\mathrm{r}$ is, $\mathrm{B}_{\mathrm{G}}\left(\mathrm{x}_{0}, \mathrm{r}\right)=\{\mathrm{y}$ $\left.\in X: G\left(x_{0}, y, y\right)<r\right\}$.

Proposition 1.1. Let $(X, G)$ be a G-metric space, then for any $\mathrm{x}_{0} \in \mathrm{X}$ and $\mathrm{r}>0$,we have,

(i) if $\mathrm{G}\left(\mathrm{x}_{0}, \mathrm{x}, \mathrm{y}\right)<\mathrm{r}$, then $\mathrm{x}, \mathrm{y} \in \mathrm{B}_{\mathrm{G}}\left(\mathrm{x}_{0}, \mathrm{r}\right)$.

(ii) if $\mathrm{y} \in \mathrm{B}_{\mathrm{G}}\left(\mathrm{x}_{0}, \mathrm{r}\right)$,then there exists a $\delta>0$ such that $\mathrm{B}_{\mathrm{G}}(\mathrm{y}, \delta) \subseteq \mathrm{B}\left(\mathrm{x}_{0}, \mathrm{r}\right)$.

Definition 1.2. Let $(X, G)$ and $\left(X^{\prime}, G^{\prime}\right)$ be G-metric spaces .A function $\mathrm{f}: \mathrm{X} \rightarrow \mathrm{X}^{\prime}$ is $\mathrm{G}$-continuous at a point $\mathrm{x}_{0} \in \mathrm{X}$ if $\mathrm{f}$ ${ }^{1}\left(B_{G}\left(f\left(x_{0}\right), r\right)\right) \in X$ for all $r>0$. We say $f$ is $G$-continuous if it is $\mathrm{G}$-continuous at all points of $\mathrm{X}$.

Proposition 1.2. Let $(X, G)$ and $\left(X^{\prime}, G^{\prime}\right)$ be $G$-metric spaces. A function $\mathrm{f}: \mathrm{X} \rightarrow \mathrm{X}^{\prime}$ is G-continuous at a point $\mathrm{x} \in \mathrm{X}$ iff it is G-sequentially continuous at $\mathrm{x}$; that is, whenever $\left(\mathrm{x}_{\mathrm{n}}\right)$ is $\mathrm{G}$ convergent to $\mathrm{x}$ we have $\left(\mathrm{fx}_{\mathrm{n}}\right)$ is G-convergent to $\mathrm{f}(\mathrm{x})$.

Proposition 1.3. Let $(X, G)$ be a G-metric space, then the function $G(x, y, z)$ is jointly continuous in all three of its variables .
Definition 1.3. Let $(X, G)$ be a $G$ - metric space. A sequence $\left\{x_{n}\right\}$ in $X$ is $G-$ convergent to $x$ if $\lim _{m, n \rightarrow \infty} G\left(x, x_{n}, x_{m}\right)=0$; i.e., for each $\in>0$ there exists an $\mathrm{N}$ such that $\mathrm{G}\left(\mathrm{x}, \mathrm{x}_{\mathrm{n}}, \mathrm{x}_{\mathrm{m}}\right)<$ $E$ for all $\mathrm{m}, \mathrm{n} \geq \mathrm{N}$.

Proposition 1.4.Let $(X, G)$ be a $G$ - metric space. Then the following are equivalent:
(i) $\left\{x_{n}\right\}$ is G convergent to $x$,
(ii) $\mathrm{G}\left(\mathrm{x}_{\mathrm{n}}, \mathrm{x}_{\mathrm{n}}, \mathrm{x}\right) \rightarrow 0$ as $\mathrm{n} \rightarrow \infty$,
(iii) $\mathrm{G}\left(\mathrm{x}_{\mathrm{n}}, \mathrm{x}, \mathrm{x}\right) \rightarrow 0$ as $\mathrm{n} \rightarrow \infty$,
(iv) $\mathrm{G}\left(\mathrm{x}_{\mathrm{m}}, \mathrm{x}_{\mathrm{n}}, \mathrm{x}\right) \rightarrow 0$ as $\mathrm{m}, \mathrm{n} \rightarrow \infty$.

Definition 1.4. Let $(X, G)$ be a $G$ - metric space. A sequence $\left\{x_{n}\right\}$ is called $\mathrm{G}-$ Cauchy if, for each $\in>0$ there exists an $N$ such that $\mathrm{G}\left(\mathrm{x}_{\mathrm{n}}, \mathrm{x}_{\mathrm{m}}, \mathrm{x}_{l}\right)<\in$ for all $\mathrm{n}, \mathrm{m}, l \geq \mathrm{N}$.

Proposition 1.6. In a $\mathrm{G}$ - metric space $(\mathrm{X}, \mathrm{G})$ the following are equivalent:

(i) the sequence $\left\{x_{n}\right\}$ is G-Cauchy,

(ii) for each $\in>0$ there exists an $\mathrm{N}$ such that $\mathrm{G}$ $\left(\mathrm{x}_{\mathrm{n}}, \mathrm{x}_{\mathrm{m}}, \mathrm{x}_{\mathrm{l}}\right)<\in$ for all $\mathrm{n}, \mathrm{m}, \mathrm{l} \geq \mathrm{N}$.

Proposition 1.7. A $\mathrm{G}$ - metric space $(\mathrm{X}, \mathrm{G})$ is $\mathrm{G}$ - complete if and only if $\left(X, d_{G}\right)$ is a complete metric space.

\section{MAIN RESULTS.}

In 2002, Branciari [1] and Rhoades [7] proved fixed point theorems for integral type contractive condition which further strengthens the Banach Fixed Point Theorem.

Now, we prove a common fixed point theorem using E.A. property for a pair of weakly compatible mappings satisfying a contractive condition of integral type in G-metric spaces.

Theorem 2.1. Let $f$ and $g$ be weakly compatible self maps of a $\mathrm{G}$ - metric space $(X, G)$ satisfying the following conditions :

(2.1) f and g satisfy E.A. property,

$$
\int_{0}^{G(f x, f y, f z)} \varphi(\mathrm{t}) \mathrm{dt} \leq \mathrm{c} \int_{0}^{G(g x, g y, g z)} \varphi(\mathrm{t}) \mathrm{dt},
$$

for each $\mathrm{x}, \mathrm{y} \in \mathrm{X}, \mathrm{c} \in[0,1)$,

where $\varphi: \mathrm{R}^{+} \rightarrow \mathrm{R}^{+}$is a Lebesgue-integral mapping which is summable (with finite integral ) on each compact subset of $\mathrm{R}^{+}$, non-negative, and such that for each $\varepsilon>0$,

$$
\int_{0}^{\varepsilon} \varphi(t) d t>0,
$$

(2.4) $\quad g(X)$ is a closed subspace of $X$. 
Then $f$ and $g$ have a unique common fixed point.

Proof. Since $f$ and $g$ satisfy the E.A. property, therefore, there exists a sequence $\left\{\mathrm{x}_{\mathrm{n}}\right\}$ in $\mathrm{X}$ such that $\lim _{n \rightarrow \infty} \mathrm{fx}_{\mathrm{n}}=\lim _{n \rightarrow \infty} \mathrm{gx}_{\mathrm{n}}=\mathrm{u}$ $\in X$. Since $g(X)$ is a closed subspace of $X$, every convergent sequence of point of $g(X)$ has a limit point in $g(X)$.

Therefore, $\lim _{n \rightarrow \infty} \mathrm{fx}_{\mathrm{n}}=\mathrm{u}=\mathrm{ga}=\lim _{n \rightarrow \infty} \mathrm{gx}_{\mathrm{n}}$ for some $\mathrm{a} \in \mathrm{X}$. This implies $\mathrm{u}=\mathrm{ga} \in \mathrm{g}(\mathrm{X})$.

Now From (2.2), we have

$$
\int_{0}^{G\left(f a, f x_{n}, f x_{n}\right)} \varphi(\mathrm{t}) \mathrm{dt} \leq \mathrm{c} \int_{0}^{G\left(g a, g x_{n}, g x_{n}\right)} \varphi(\mathrm{t}) \mathrm{dt} .
$$

Letting $\mathrm{n} \rightarrow \infty$ and using Lebesgue dominatd convergence theorem and $c \in[0,1)$ it follows in view of (2.3) that $u=f a$. This implies $\mathrm{u}=\mathrm{ga}=\mathrm{fa}$. Thus $\mathrm{a}$ is the coincidence point of $\mathrm{f}$ and $\mathrm{g}$.

Since $\mathrm{f}$ and $\mathrm{g}$ are weakly compatible, therefore, $\mathrm{fu}=\mathrm{fga}=\mathrm{gfa}$ = gu.

From (2.2), we have

$$
\int_{0}^{G(f u, f a, f a)} \varphi(\mathrm{t}) \mathrm{dt} \leq \mathrm{c} \quad \int_{0}^{G(g u, g a, g a)} \varphi(\mathrm{t}) \mathrm{dt} \text {, since } \mathrm{c} \in
$$

$[0,1)$, which in turns implies that $f u=u$. Hence $u$ is the unique common fixed point of $f$ and $g$.

For uniqueness: Suppose that $\mathrm{w}(\neq \mathrm{z})$ is also another common fixed point of $f$ and g. From (2.2), we have

$$
\begin{gathered}
\int_{0}^{G(z, w, w)} \varphi(\mathrm{t}) \mathrm{dt}=\int_{0}^{G(f z, f w, f w)} \varphi(\mathrm{t}) \mathrm{dt} \leq \mathrm{c} \\
\int_{0}^{G(g z, g w, g w)} \varphi(\mathrm{t}) \mathrm{dt}=\mathrm{c} \int_{0}^{G(z, w, w)} \varphi(\mathrm{t}) \mathrm{dt}, \text { since } \mathrm{c} \in
\end{gathered}
$$

$[0,1)$, therefore, $\mathrm{z}=\mathrm{w}$ and uniqueness follows .

Example 2.1. Consider $X=[0,2]$ with usual G- metric space $\mathrm{G}$.i.e., $\mathrm{G}(\mathrm{x}, \mathrm{y}, \mathrm{z})=($ $|x-y|+|y-z|+|z-x|)$. Define the self maps $\mathrm{f}$ and $\mathrm{g}$ on $\mathrm{X}$ as follows:

$$
0\{\text { if } 0 \leq x<1 \quad 0 \text { if } 0 \leq x<1
$$

$f(x)=\left\{\begin{array}{l}1 \text { if } 1 \leq x \leq 2 \quad g(x)=\quad 2, \text { if } 1 \leq x \leq 2 .\end{array}\right.$

Consider the sequence $\mathrm{x}_{\mathrm{n}}=\frac{1}{n}$. Clearly $\lim _{n \rightarrow \infty} \mathrm{fx}_{\mathrm{n}}=\lim _{n \rightarrow \infty} \mathrm{gx}_{\mathrm{n}}$ $=0$.Then $\mathrm{f}$ and $\mathrm{g}$ satisfy E. A . property. Also $\mathrm{f}(\mathrm{X})=\{0,1\}$ and $g(X)=\{0,2\}$. Here we note that neither $f(X)$ is contained in $g(X)$ nor $g(X)$ is contained in $f(X)$.

Moreover $\varphi$ defined by $\varphi(t)=t$ is a Lebesgue-integral mapping which is summable (with finite integral) on each compact subset of $\mathrm{R}^{+}$, non-negative, and such that for each $\varepsilon>0$,

$$
\int_{0}^{\varepsilon} \varphi(t) d t>0 \text {. Theorem } 2.1 \text { holds for } \frac{1}{2} \leq q<1 \text {. }
$$

Theorem 2.2. Let $\mathrm{f}$ and $\mathrm{g}$ be weakly compatible self maps of a G- metric space $(\mathrm{X}, \mathrm{G})$ satisfying $(2.1),(2.2),(2.3)$ and the following :

(2.5) $\mathrm{f}(\mathrm{X}) \subset \mathrm{g}(\mathrm{X})$.

If the range of either of $f$ or $g$ is a closed subspace of $X$, then $f$ and $\mathrm{g}$ have a unique common fixed point.

Proof follows easily from Theorem 2.1.

\section{REFERENCES}

[1] A. Branciari, A fixed point theorem for mappings satisfying a general contractive condition of integral type, Int. J. Math. Math. Sci.,29(9) (2002), 531-536.

[2] G. Jungck, Common fixed points for noncontiguous nonelf mappings on metric spaces, Far East J. Math. Sci.4 (2), (1996), 199-212

[3] Z. Mustafa and B.Sims, Some remarks concerning Dmetric spaces, Proceedings of International Conference on Fixed Point Theory and applications, Yokohama Publishers, Valencia Spain, July 13-19(2004), 189-198.

[4] Z.Mustafa and B.Sims, A new approach to a generalized metric spaces, J. Nonlinear Convex Anal., 7(2006), 289-297.

[5] Z.Mustafa and H.Obiedat and F.Awawdeh, Some fixed point theorems for mappings on complete G-metric spaces, Fixed point theory and applications , Volume2008, Article ID 18970,12 pages.

[6] Z.Mustafa,W. Shatanawi and M.Bataineh, Existence of fixed points results in G- metric spaces ,International Journal of Mathematics and Mathematical Sciences, Volume 2009, Article ID. 283028, 10 pages.

[7] B. E. Rhoades, Two fixed point theorems for mappings satisfying a general contractive condition of integral type, Int. J. Math. Math. Sci., 63(2003), 4007-4013. 